\title{
Lysosome mediates toxicological effects of polyethyleneimine-based cationic carbon dots
}

Carole Ronzania, Camille Van Bellea, Pascal Didierb, Coralie Spiegelhalterc, Philippe Pierrata, Luc Lebeau ${ }^{a}$, Françoise Pons ${ }^{\mathrm{a}, *}$

aLaboratoire de Conception et Application de Molécules Bioactives, UMR 7199, CNRS-Université de Strasbourg, Faculté de Pharmacie, Illkirch, France

bLaboratoire de Bioimagerie et Pathologies, UMR 7021, CNRS-Université de Strasbourg, Faculté de Pharmacie, Illkirch, France

cCentre d'Imagerie, Institut de Génétique et de Biologie Moléculaire et Cellulaire, Illkirch, France

*Corresponding author. E-mail: pons@unistra.fr (Françoise Pons); Phone: (+33) 368854203 


\begin{abstract}
Cationic carbon dots (CDs) have been recently described as nucleic acid carriers with high in vitro and in vivo transfection efficiency and imaging properties. However, developing nanoparticles for biomedical applications requires assessing their safety. In the present study, we characterized the cell uptake and trafficking, as well as the cell viability loss, oxidative stress, inflammation and mitochondrial and lysosomal perturbations evoked by cationic CDs prepared by microwave-assisted pyrolysis of citric acid and high molecular weight branched polyethyleneimine (bPEI25k), using THP-1-derived macrophages. CDs were rapidly internalized by cells and addressed to the lysosomes after their cell entry. The NPs induced a dose- and timedependent loss in cell viability that was associated with oxidative stress and IL-8 release. The CDs triggered also a dose-dependent loss in lysosome integrity, mitochondrial dysfunction and NLRP3 inflammasome activation. Inhibition of the lysosomal protease cathepsin B significantly reduced CD-induced mitochondrial dysfunction and NLRP3 inflammasome activation, suggesting a pivotal role of the lysosome in the toxicological effects of the NPs. Our study provides for the first time a mechanistic pathway for the toxicological effects of bPEI25k-based cationic CDs.
\end{abstract}

Keywords: nanoparticles ; carbon dots ; nanotoxicology ; lysosome ; oxidative stress ; inflammation 


\section{Introduction}

Carbon dots (CDs) are the last member of the carbon nanoparticle (NP) family. They were serendipitously discovered in 2004 (Xu et al. 2004) and since then, they have gained huge attention from researchers due to their unique properties, including very small size (a few nanometers), water solubility, intrinsic fluorescence, ease of synthesis (from simple inexpensive carbon sources) and functionalization (allowing customization of their surface charge and chemistry) (Himaja et al. 2015; Kwon et al. 2014; Sachdev et al. 2014; Tian et al. 2014). CDs may be prepared by top-down or bottom-up approaches. In the most popular bottom-up approach, these NPs are produced during the pyrolysis of organic matter and hence are naturally present, e.g., in soot (Liu et al. 2007) and foodstuffs such as caramels (Sk et al. 2012) or soluble instant coffee (Jiang et al. 2014).

CDs are currently widely studied for potential applications in biomedicine in relation to their unique photoluminescence properties (Wang and Qiu 2016). Fluorescent CDs with superior photostability are developed for optical imaging applications as an alternative to semiconductor quantum dots that raise health and environmental concerns due to the heavy metal typically found in their composition (Edison et al. 2016; Qian et al. 2014; Ray et al. 2009; Stefanakis et al. 2014; Yang et al. 2009). Besides, CDs have gradually emerged as a versatile platform for the design of novel nanocarriers for the delivery of therapeutic agents such as paclitaxel or doxorubicin (Gomez et al. 2018; Yuan et al. 2017; Zhang et al. 2017). Interestingly, exacerbation of the photoluminescence properties of CDs can be achieved through surface-passivation of the particles with nitrogen-containing reagents. This may result in cationic particles that are ready to form complexes with nucleic acids through electrostatic interactions and may thus be used as gene delivery systems (Hosseinkhani 2006), as it was demonstrated in vitro (Dou et al. 2015; Hu et al. 2014; Liu et al. 2012; Pierrat et al. 2015; Wang et al. 2014; Yang et al. 2017). Recently, our group reported the synthesis of such cationic CDs by microwave-assisted pyrolysis of citric acid and high molecular weight branched polyethyleneimine (bPEI25k), and the ability of these CDs to efficiently deliver genes into the lung of mice (Pierrat et al. 2015). Noteworthy, these CDs favorably compare with GL67A, the current gold standard formulation for pulmonary administration of DNA. Thus, cationic CDs have great potential for nucleic acid delivery, while also offering imaging possibilities, paving a new avenue for developing theranostic tools for gene therapy (Cao et al. 2018; Kim et al. 2017).

However, because of their specific properties at the nanoscale, engineered NPs raise safety concerns (Nel et al. 2006). Although carbon is not considered as a toxic element, carbon-based nanomaterials such as carbon nanotubes (CNTs) or $\mathrm{C}_{60}$-fullerenes have been shown to exhibit 
adverse effects in function of their shape, size, functional groups at their surface, or other physicochemical parameters (Li et al. 2013; Ronzani et al. 2012; Salieri et al. 2017). Therefore, developing CDs for biomedical applications requires assessing not only their efficacy, but also their toxicological properties prior to further developments for the clinic. In the literature, CDs have been so far reported to cause little if any toxicity, and are therefore considered as biocompatible (Blas-Garcia et al. 2016; Edison et al. 2016; Emam et al. 2017; Lategan et al. 2018; Li et al. 2015; Qian et al. 2014; Ray et al. 2009; Wang et al. 2013; Yang et al. 2009). However most studies were conducted on pristine CDs or on CDs that were surface-passivated with poly(ethylene glycol) (PEG), which is a biocompatible and biodegradable polymer used to prevent protein adsorption on NPs and therefore recognition of the latter by the immune system. These studies may thus not properly reflect some possible toxicological effects of CDs on living cells.

Surface charge is well known for its drastic influence on nanomaterials biocompatibility (El Badawy et al. 2011; Kim et al. 2016; Li et al. 2013; Shahbazi et al. 2013). Regarding CDs, some authors reported that cationic CDs prepared from bPEI25k exhibit some cytotoxicity towards cells of various tissue origins (Liu et al. 2012; Pierrat et al. 2015). Furthermore, a comparative study recently demonstrated that CDs prepared from candle soot and subsequently coated with PEI, so they display a net positive charge, were more toxic towards cultured fibroblasts than negatively charged pristine CDs (Havrdova et al. 2016). Therefore, as previously reported for silicon- (Shahbazi et al. 2013), silver- (El Badawy et al. 2011), or polystyrene-based NPs (Kim et al. 2016), or for CNTs (Li et al. 2013), the surface charge seems to impact on CD safety, a cationic charge being associated with higher toxicological risks. However, the mechanisms involved in the cytotoxicity of cationic CDs remain poorly explored.

To date, one of the main mechanisms incriminated in the toxicity of NPs is oxidative stress that triggers inflammation and, in the worst case, causes cell death (Hussain et al. 2009; Marano et al. 2011). Some other mechanisms have been proposed that bring into play lysosomal dysfunction and/or injury (Stern et al. 2012). Indeed, since 1-endocytosis is the main way for NPs to enter into cells and 2-lysosomes are the terminal components of the endo/lysosomal system, most NPs end up in lysosomes after their cell uptake (Zhao et al. 2011). Trafficking of positively charged particles made of cationic polymer, such as PEI-passivated CDs, to the lysosome may elicit the so-called "proton sponge effect», as it was described for PEI-based transfection particles (Boussif et al. 1995). According to the proton sponge hypothesis, endosome buffering by PEI provokes accumulation of protons brought in by the endosomal ATPase, which is coupled to an influx of chloride anions. This does result in a large increase in ionic strength in the compartment, with subsequent osmotic swelling and endosome membrane 
permeabilization or disruption allowing NPs to escape into the cytosol. However, this trafficking might also trigger cellular damages, as lysosomal injury may result in the release of the organelle content into the cytosol. Among this content, proteases such as cathepsins can induce mitochondrial dysfunction, NLRP3 (NOD-like receptor pyrin domain-containing-3) inflammasome activation and, in the more critical cases, cell death by apoptosis or necrosis (Boya and Kroemer 2008; Repnik et al. 2014). However, the role of lysosomes in the toxicological effects of PEI-based CDs has not been investigated yet and remains unknown. In this context, we characterized the cell uptake, trafficking, and toxicological properties of CDs prepared from bPEI25k in THP-1-derived human macrophages, and we investigated the implication of the lysosome in the cellular responses evoked by the NPs. 


\section{Material and methods}

\section{Preparation and characterization of CDs}

Fluorescent CDs were synthesized by a microwave-assisted pyrolysis route, based on a previous report (Pierrat et al. 2015). Briefly, citric acid (0.50 g, from Merck, Darmstadt, Germany) was mixed with branched PEI (0.25 g, MW 25kDa, bPEI25k, from Sigma-Aldrich, St Louis, MO, USA) in $\mathrm{HCl} 0.1 \mathrm{~N}(5 \mathrm{~mL})$ in a $100 \mathrm{~mL}$ Erlenmeyer flask. The homogeneous solution was submitted for $240 \mathrm{~s}$ to microwave radiation in a $23 \mathrm{~L}$ domestic oven with a triple wave distribution system (TDS Silver ME82V, Samsung) at a power output of $450 \mathrm{~W}$. The reaction mixture was then cooled to room temperature, ultrapure water $(5 \mathrm{~mL})$ was added, and the resulting solution was centrifuged ( $5000 \mathrm{rpm}, 5 \mathrm{~min}$ ). The supernatant was filtered over a $0.22 \mu \mathrm{m}$ membrane, loaded into a dialysis tubing (Spectra/Por 3, MWCO $3500 \mathrm{Da}$ ), and equilibrated against $500 \mathrm{~mL} \mathrm{HCl} 0.1$ $\mathrm{N}$ for $24 \mathrm{~h}$ (dialysate was replaced after 2, 6, and $12 \mathrm{~h}$ ), and then against ultrapure water for $48 \mathrm{~h}$ (dialysate was replaced once every $12 \mathrm{~h}$ ). Dialysis procedures used herein allowed efficient removal of unreacted bPEI25k, yielding CD samples containing less than $6 \%$ of unreacted polymer. The residual dialysis bag content was lyophilized to yield a light brown powdered and hygroscopic material (158 mg).

NMR spectra from samples prepared in deuterium oxide were recorded on a Bruker $400 \mathrm{MHz}$ Avance III instrument. ${ }^{1} \mathrm{H}$ - and ${ }^{13} \mathrm{C}-\mathrm{NMR}$ chemical shifts $\delta$ are reported in ppm relative to $t$ - $\mathrm{BuOH}$ as an internal reference $\left({ }^{1} \mathrm{H}:\left(\mathrm{C}_{3}\right)_{3} \mathrm{COH}\right.$ at $1.24 \mathrm{ppm}$; ${ }^{13} \mathrm{C}:\left(\underline{\mathrm{CH}}_{3}\right)_{3} \mathrm{COH}$ at $\left.30.29 \mathrm{ppm}\right)$. Fourier transform infrared spectroscopy (FT-IR) was performed on a FT-IR Nicolet 380 spectrometer in the ATR mode. The elemental composition of CDs was determined by analysis on an ElementarVario EL III apparatus. Absorption and photoluminescence spectra were recorded from samples prepared in ultra pure water $(0.50 \mathrm{mg} / \mathrm{mL})$, with a SAFAS Xenius XC spectrofluorimeter (SAFAS, Monaco) using a 1-mL quartz cuvette. Fluorescence spectra were recorded with excitation at $360 \mathrm{~nm}$. Fluorescence quantum yield ( $\Phi_{\mathrm{CD}}$ ) was determined in water using quinine sulfate (qs) in $0.5 \mathrm{~N} \mathrm{H}_{2} \mathrm{SO}_{4}$ as standard $\left(\Phi_{\mathrm{qs}}=0.54\right)$ and was calculated according to

$\Phi_{\mathrm{CD}}=\Phi_{\mathrm{qs}} \cdot\left(\mathrm{F}_{\mathrm{CD}} / \mathrm{F}_{\mathrm{qs}}\right) \cdot\left(\mathrm{A}_{\mathrm{qs}} / \mathrm{A}_{\mathrm{CD}}\right)$

where $\Phi_{\mathrm{CD}}$ and $\Phi_{\mathrm{qs}}$ were the quantum yields for CDs and quinine sulfate (resp.), $\mathrm{F}_{\mathrm{CD}}$ and $\mathrm{F}_{\mathrm{qs}}$ were the measured integrated emission intensities, and $\mathrm{A}_{\mathrm{CD}}$ and $\mathrm{A}_{\mathrm{qs}}$ were the absorbances. In order to minimize fluorescence quenching, absorbance in the $10 \mathrm{~mm}$ fluorescence cuvette was kept below 0.10 at the excitation wavelength $(360 \mathrm{~nm})$. 
The average particle size (hydrodynamic diameter) and zeta potential ( $\zeta$ ) of CDs were measured by dynamic light scattering (DLS) using a ZetasizernanozS apparatus (Malvern Instruments, Paris, France). Measurements were performed in triplicate on freshly prepared

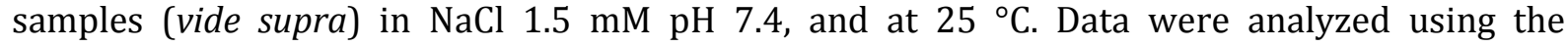
multimodal number distribution software supplied with the instrument and expressed as mean $( \pm$ SD). The primary shape and morphology of CDs were captured by transmission electron microscopy (TEM) using a bench top transmission electron microscope operating at $5 \mathrm{kV}$ (LVEM5, Cordouan Technologies, Pessac, France). Carbon-coated grids (Cu-300HD, Pacific Grid Tech, San Francisco, USA) were glow discharged at $90 \mathrm{~V}$ and $2 \mathrm{~mA}$ for $15 \mathrm{~s}$ before deposition of the CD samples $(0.5 \mu \mathrm{L}, 1 \mathrm{mg} / \mathrm{mL})$. The grids were allowed to dry at room temperature for at least $2 \mathrm{~h}$ before observation. Average size of the particles was determined by image analysis using the Image J software (v 1.50i, NIH, USA), from a set of 300-1000 particles.

\section{Cell culture}

Non activated THP- 1 cells (TIB-202 ${ }^{\mathrm{TM}}$, ATCC) were grown in culture flasks at $37^{\circ} \mathrm{C}$ in a $5 \% \mathrm{CO}_{2}$ humidified chamber using RPMI-1640 culture medium containing $2 \mathrm{mM}$ L-glutamine, $0.05 \mathrm{mM}$ 2-mercaptoethanol, $100 \mathrm{UI} / \mathrm{mL}$ penicillin, $100 \mu \mathrm{g} / \mathrm{mL}$ streptomycin and $10 \%$ heat inactivated FBS (all reagents from GIBCO). For experiments, cells were seeded in appropriated culture devices and differentiated into macrophages overnight by adding $10 \mathrm{ng} / \mathrm{mL}$ phorbolmyristate acetate (PMA, Sigma-Aldrich) to the culture medium.

\section{CD cell uptake and trafficking to the lysosomes}

CD cell uptake and trafficking were assessed by TEM and confocal laser scanning microscopy (CLSM). For TEM experiments, cells were seeded on cover slips at a density of $6.5 \times 10^{5}$ cells/well, differentiated into macrophages and exposed to CDs for $4 \mathrm{~h}$. After CD incubation, they were carefully rinsed with PBS and fixed with $2.5 \%$ glutaraldehyde, $4 \%$ formaldehyde in $0.1 \mathrm{M}$ phosphate buffer. Cells were then post-fixed with $1 \%$ osmium tetroxide, dehydrated in acetone and embedded in an epoxy resin. Ultrathin tissue sections $(60 \mathrm{~nm})$ were collected on grids and observed using a CM12 Philips microscope operated at $80 \mathrm{kV}$. Image acquisition was done with an Orius 1000 CCD camera (Gatan). For CLSM experiments, cells were seeded into 8-Well

IbiTreat $\mu$-Slides (1.5 polymer coverslip, IBIDI ${ }^{\circledR}$ ) at a density of $10^{5}$ cells/well, differentiated into macrophages, and incubated with CDs for 1 or $4 \mathrm{~h}$. At the end of the incubation time, the cells were carefully washed with culture medium to remove non-internalized CDs. For internalization experiments, the DSQ12S fluorescent probe (10 nM in PBS) (Collot et al. 2015) was added to the 
samples for 5 min to label the cell membrane. For colocalization experiments, the cells were stained with the LysoTracker ${ }^{\circledR}$ Red DND-99 fluorescent probe (Molecular Probes, Eugene, Oregon, USA) for $30 \mathrm{~min}$ to label lysosomal organelles. The intracellular distribution of CDs was observed using a Leica SP2 microscope equipped with a $63 \mathrm{x}$ oil immersion objective (NA=1.2). CDs, the DSQ12S membrane probe and the LysoTracker ${ }^{\circledR}$ Red were excited with 405, 635, and $561 \mathrm{~nm}$ laser sources, respectively. The emission bands were detected with a photomultiplier. The position and the width of the detection channels were adjusted for each dye. To quantify CD internalization, analysis of CD fluorescence intensity was conducted on at least 200 cells from 2 or 3 biological replicates. In order to determine the degree of colocalization between CDs and lysosomes, the following protocol was applied: individual spots were identified with the "Localization microscopy" plugin developed by N. Stuurman for MicroManager (Edelstein et al. 2014). In practice, for each individual frame, a region of interest of $15 \times 15$ pixels (1710x1710 $\mathrm{nm}$ ) was defined. Then, spatially separated point spread function signals emitted by diffraction limited complexes were detected by means of local maxima and fitted with a two-dimensional Gaussian distribution. By using this approach, it was possible to obtain the positions of endosomes (LysoTracker ${ }^{\circledR}$ Red) and of CDs for each individual image. Next, the position list obtained for a specific channel was used to determine the presence or the absence of the other color. To avoid false positive, a threshold was used to filter out spots with a fluorescence signal below twice the background level. By applying this method it was possible to generate a colocalization trace (color $1 \mathrm{vs}$. color 2) from which the degree of colocalization can be obtained through determination of a Pearson's correlation coefficient.

\section{Cell viability assessment}

Changes in cell viability in response to CDs were assessed by the MTT assay. Cells were seeded into 96-well culture plates at a density of $10^{5}$ cells/well, differentiated into macrophages and incubated with increasing concentrations of CDs $(3-200 \mu \mathrm{g} / \mathrm{mL})$ for 1,4 or $24 \mathrm{~h}$. After the incubation with CDs, culture medium was removed and stored at $-80{ }^{\circ} \mathrm{C}$ until IL-8 assay, and cells were carefully washed with PBS before addition of complete culture medium containing MTT (100 $\mu \mathrm{L}$ of a $1.0 \mathrm{mg} / \mathrm{mL}$ solution). After dye incubation for $1 \mathrm{~h}$, culture medium was removed and cells were lysed with DMSO. Absorbance of the resulting samples was read at 570 $\mathrm{nm}$ with a correction at $690 \mathrm{~nm}$ using a Multiskan FC reader (Thermo Scientific). Cell viability was expressed as the percentage of the absorbance of treated cells relative to the absorbance of the non-exposed control cells. 


\section{Neutral red assay}

Neutral red (NR) assay was used to assess lysosomal membrane integrity. Cells were seeded into 96-well culture plates at a density of $10^{5}$ cells/well, differentiated into macrophages, and incubated with increasing concentrations of CDs for $24 \mathrm{~h}$. At the end of the incubation period, culture medium was removed and cells were carefully washed with PBS. Complete culture medium containing NR (200 $\mu \mathrm{L}$ of a $100 \mu \mathrm{g} / \mathrm{mL}$ solution) was added to the cells for dye incorporation into intact lysosomes. After a 3-h incubation period, culture medium was removed and cells were lysed with $1 \%$ acetic acid solution containing $50 \%$ ethanol to release the incorporated dye. Absorbance of the resulting samples was read at $570 \mathrm{~nm}$ with a correction at $690 \mathrm{~nm}$. Results were expressed as the percentage of the absorbance of treated cells relative to the absorbance of the non-exposed control cells.

\section{Oxidative stress assessment}

Oxidative stress was assessed by measuring changes in reactive oxygen species (ROS) and reduced glutathione (GSH) cellular levels in response to CDs. Cells were seeded into 24-well culture plates at a density of $5 \times 10^{5}$ cells/well, differentiated into macrophages and incubated for $4 \mathrm{~h}$ with increasing concentrations of CDs, or with $100 \mathrm{mM} \mathrm{H}_{2} \mathrm{O}_{2}$ as a positive control. ROS production in response to CDs was measured using the fluorescent probe $\mathrm{H}_{2}$ DCF-DA $\left(2^{\prime}, 7^{\prime}\right.$ dichlorodihydrofluoresceine diacetate, Sigma). Briefly, cells were incubated with PBS containing $20 \mu \mathrm{M}$ of the probe for $1 \mathrm{~h}$ and then washed with PBS before exposure to CDs. At the end of the CD exposure, fluorescence of each sample was measured $\left(\lambda_{\mathrm{ex}}=488 \mathrm{~nm} ; \lambda_{\mathrm{em}}=525 \mathrm{~nm}\right)$ using a Varioskan multimode reader (Thermo Scientific). Results were expressed as the percentage of the fluorescence intensity of CD-exposed cells relative to the intensity of the non-exposed control cells. Reduced GSH was measured using the 2,3-naphthalenedialdehyde probe (NDA). At the end of the CD exposure, cells were washed with $5 \mathrm{mM}$ EDTA, $40 \mathrm{mM} \mathrm{NaH} \mathrm{PO}_{4}, 110 \mathrm{mM}$ $\mathrm{Na}_{2} \mathrm{HPO}_{4}$, pH 7,4 and lysed with $0.1 \%$ Triton X100 ${ }^{\circledR}$. Then, proteins were denatured and precipitated ( $0.1 \mathrm{M}$ hydrochloric acid, $50 \%$ sulfosalicylic acid) before sample centrifugation $\left(10,000 \mathrm{~g}, 15 \mathrm{~min}, 4^{\circ} \mathrm{C}\right)$. Cell lysates were then incubated with the NDA probe for $25 \mathrm{~min}$ at $4{ }^{\circ} \mathrm{C}$, before fluorescence measurement $\left(\lambda_{\mathrm{ex}}=485 \mathrm{~nm} ; \lambda_{\mathrm{em}}=528 \mathrm{~nm}\right)$. A calibration curve was used to calculate the amount of reduced GSH in the samples. This amount was then expressed in nmol of GSH per mg of protein. To do so, protein concentration in cell lysates was determined using the bicinchoninic assay (BCA, Sigma) according to the manufacturer's instructions.

\section{Mitochondrial membrane potential assay}


Mitochondrial membrane potential was assayed using the JC-10 fluorescent probe (Sigma) according to the manufacturer's instructions. Cells were seeded into 96-well culture plates at a density of $10^{5}$ cells/well, differentiated into macrophages, and incubated with increasing concentrations of CDs for $4 \mathrm{~h}$. In some experiments, cells were pre-treated for $1 \mathrm{~h}$ with a cathepsin B inhibitor (CA-074Me, $100 \mu \mathrm{M}$, Enzo Life). After the CD treatment, the cell culture supernatant was removed and the JC-10 probe $(100 \mu \mathrm{L})$ was added to the cells for $1 \mathrm{~h}$. Then, fluorescence of the samples was measured (functional mitochondria: $\lambda_{\mathrm{ex}}=540 \mathrm{~nm}, \lambda_{\mathrm{em}}=590 \mathrm{~nm}$; non functional mitochondria: $\lambda_{\mathrm{ex}}=490 \mathrm{~nm}, \lambda_{\mathrm{em}}=525 \mathrm{~nm}$ ). The ratio of fluorescence intensity at $525 \mathrm{~nm}$ to fluorescence intensity at $590 \mathrm{~nm}$ was calculated for each sample. Then, data were expressed as the percentage of fluorescence of $\mathrm{CD}$-exposed cells relative to the fluorescence ratio of non-exposed control cells.

\section{NLRP3 inflammasome activation}

NLRP3 inflammasome activation was determined by measuring IL-1 $\beta$ secretion from CD-treated cells. Cells were seeded into 96-well culture plates at a density of $10^{5}$ cells/well, differentiated into macrophages and incubated with increasing concentrations of CDs for $4 \mathrm{~h}$. In some experiments, cells were pre-treated for $1 \mathrm{~h}$ with a caspase-1 inhibitor (Z-WEHD, $10 \mu \mathrm{M}$, BioTechne) or the cathepsin B inhibitor CA-074Me $(100 \mu \mathrm{M})$ before exposure to CDs. After CD treatment, cell culture supernatants were removed and stored at $-80^{\circ} \mathrm{C}$ until IL- $1 \beta$ assay.

\section{Cytokine assay}

IL-8 and IL-1 $\beta$ were quantified in cell culture supernatants by enzyme-linked immunosorbent assays (R\&D Systems) according to the manufacturer's instructions. Absorbance was read at $450 \mathrm{~nm}$ with a correction at $570 \mathrm{~nm}$. Calibration curves were used to calculate the cytokine concentrations, expressed in $\mathrm{pg} / \mathrm{mL}$.

\section{Statistical analysis}

Data are presented as mean \pm SEM. Dose-response curves were obtained after logarithmic transformation of the data and fit with the Hill's equation, whose slope was used to calculate the $\mathrm{EC}_{50}$. Statistical differences between groups were determined by analysis of variance (ANOVA) followed by Tukey's or Dunnett's test, using the GraphPad Prism 6.0 software. Data were considered as significantly different when $p<0.05$. 


\section{Results and Discussion}

\section{Characterization of CDs}

Our group previously reported a straightforward methodology for the preparation of cationic CDs for gene therapy and bioimaging (Pierrat et al. 2015). Using this methodology, fully watersoluble CDs were obtained in $c a .20 \%$ yield from citric acid and bPEI25k by microwave-assisted pyrolysis under normal pressure. To provide detailed information about the physicochemical properties of the as-produced CDs, the corresponding comprehensive characterizations including that of size, surface charge, morphology, ${ }^{1} \mathrm{H}$ - and ${ }^{13} \mathrm{C}-\mathrm{NMR}$, elemental composition, and optical properties were carried out.

The morphology and size of the CDs were characterized at pH 7.4 by TEM and DLS. The TEM images showed quasi-spherical particles with an average size of $13.6 \mathrm{~nm}$ (Fig. 1a). The size distribution from DLS measurements was fully consistent with the TEM results, indicating an average diameter of $12.9 \pm 3.0 \mathrm{~nm}$ (Fig. 1b). The zeta potential of the CDs was determined as $+43.2 \pm 8.5 \mathrm{mV}$, indicating a highly positive surface that provided colloidal stability to the NPs and prevented the formation of aggregates. Indeed, aqueous solution of CDs proved stable for several months at $4{ }^{\circ} \mathrm{C}$ as was demonstrated by regular size and zeta potential measurements (data not shown).

The ${ }^{1} \mathrm{H}$-NMR spectrum obtained for the CD particles (Fig. 1c) showed a $0.33 \mathrm{ppm}$ downfield shift of the $A B$ system corresponding to the methylene protons $\left(\mathrm{CH}_{2} \mathrm{COOH}\right)$ in citric acid. Conversely, the signal for PEI amino methylene groups initially at $2.55-2.75 \mathrm{ppm}$ was drastically shifted upfield (2.8-3.5 ppm) in the PEI-passivated CDs. The signals for all protons were significantly broadened in comparison with those in free PEI and citric acid molecules, where the broadening effect is consistent with the attachment to NPs as larger species of lower mobility (thus slower isotropic averaging) (Terrill et al. 1995), and also with the inhomogeneous distribution of sites at the surface of the carbon NPs (Marega et al. 2009). ${ }^{13} \mathrm{C}-\mathrm{NMR}$ spectroscopy as a powerful technique for distinguishing $\mathrm{sp}^{3}$ from $\mathrm{sp}^{2}$ carbons was used to identify the types of carbon centers in the CDs and gain further structural insights into the carbon NPs. The ${ }^{13} \mathrm{C}-\mathrm{NMR}$ spectrum of CDs showed a featureless profile in the range of 120 to $150 \mathrm{ppm}$ corresponding to $\mathrm{sp}^{2}$ carbons (Fig. 1d). This indicates that CDs do not incorporate much aromatic carbons and thus enter the "carbon nanodots" family, according to the Valcárcel's classification (Cayuela et al. 2016). Consequently, most carbon resonances were observed between 35 and 55 ppm, revealing $\mathrm{sp}^{3}$ amino methylene carbons. Besides, signals in the range of 170 to $190 \mathrm{ppm}$ arising from carboxylic and carbonyl carbons were pretty strong. The presence of carboxylic and carbonyl 
functional groups was further supported by FT-IR measurements (Fig. 1e). The broad peak centered at $3344 \mathrm{~cm}^{-1}$ was attributed to the $\mathrm{O}-\mathrm{H}$ vibrational stretch of the carboxylic moieties (and residual water), the one at $1710 \mathrm{~cm}^{-1}$ to $\mathrm{C}=0$ vibration, and the peaks at $1372 \mathrm{~cm}^{-1}$ and $1557 \mathrm{~cm}^{-1}$ to the symmetric and asymmetric carboxylate stretch, respectively (Pretsch et al. 2000). On the other hand, the characteristic N-H and C-H absorptions at $3500-3100 \mathrm{~cm}^{-1}$ and 2950-2800 $\mathrm{cm}^{-1}$, respectively, observed for bPEI25k were not so much attenuated in the CD sample, revealing that precursor PEI was not fully sacrificed in the microwave-assisted carbonization process. This is in agreement with the summary picture of the one-pot processing that citric acid is more for being carbonized into the NP core, and PEI more for the surface passivation of the resulting CDs. It is worth to note that the FT-IR features of the CDs described herein are significantly different from those of CDs prepared from the same starting materials but using conventional solvothermal pyrolysis (Hou et al. 2017), which is indicative that the outcome of the pyrolysis reactions tightly depends on the solvent conditions. Elemental composition of the NPs was determined as well and confirmed the high nitrogen content $(\mathrm{N}$ : $16.93 \pm 0.33 \%$; C: $40.64 \pm 0.13 \%$; H: $8.16 \pm 0.01 \%$ ).

In order to reveal the imaging properties of the CDs, the UV-vis absorption and fluorescence emission spectra were recorded (Fig. 1f). The CDs showed a clear absorption peak at $356 \mathrm{~nm}$ ascribed to the $n-\pi^{*}$ transition of carbonyl groups (Hao et al. 2016), with a shoulder peak at $395 \mathrm{~nm}$ indicating the presence of lower energy states resulting from functional-surface states (Das et al. 2014). The maximum fluorescence excitation and emission wavelengths were 371 and $442 \mathrm{~nm}$, respectively, with a quantum yield of $20.7 \%$. Emission was not excitation-dependent as was shown for other PEI-based CDs (Hou et al. 2017; Kim et al. 2017; Kundu et al. 2018).

\section{Effect of CDs on cell viability}

Different cellular models can be used to explore the safety of engineered NPs. These models can be selected according to potential route of exposure to these materials or organs of delivery after body absorption, but other selection criteria are possible as well. As 1-macrophages are involved in the body defense against particles, but may also contribute to pathological conditions by releasing a large number of inflammatory mediators, and 2-NLRP3 inflammasome is expressed in these cells, we selected a widely used model of human macrophages, namely PMA-activated THP-1 cells. In this model, the cytotoxicity of CDs was characterized using the MTT assay. Exposure of cells to $3-200 \mu \mathrm{g} / \mathrm{mL}$ CDs for 1,4 , or $24 \mathrm{~h}$ resulted in a dose- and time-dependent decrease in cell viability (Fig. 2). A maximum loss of viability of nearly $90 \%$ was observed at CD concentrations ranging from 100 to $200 \mu \mathrm{g} / \mathrm{mL}$ after a 1-h exposure. The values of the half 
maximal effective concentration $\left(\mathrm{EC}_{50}\right.$ ) calculated with the Hill's equation were $32.25 \mu \mathrm{g} / \mathrm{mL}$ (95\% confidence interval-CI95: 28.74 to $36.18 \mu \mathrm{g} / \mathrm{mL}$ ), $19.82 \mu \mathrm{g} / \mathrm{mL}$ (CI ${ }_{95}: 17.64$ to $22.27 \mu \mathrm{g} / \mathrm{mL}$ ) and $14.38 \mu \mathrm{g} / \mathrm{mL}\left(\mathrm{CI}_{95}: 12.95\right.$ to $15.96 \mu \mathrm{g} / \mathrm{mL}$ ) at 1,4 , and $24 \mathrm{~h}$, respectively. Thus, in agreement with our previous study in human lung epithelial cells (Pierrat et al. 2015), we found that CDs obtained from citric acid and bPEI25k by microwave-assisted pyrolysis are cytotoxic to human macrophages. So far a large panel of CDs prepared from various carbon source and passivation agents through different synthesis processes have been developed for biological applications (Wang and Qiu 2016). Although most of these CDs were described as biocompatible, their safety has been shown to depend on their surface passivation (Wang et al. 2011). In our study, the use of bPEI25k as passivation agent results in the production of CDs with a high density of polyamine groups at their surface that provides the NPs with a positive charge. This cationic charge may favor interation of CDs with the cell membrane resulting in biological and toxicological responses, as discussed below. A charge effect hypothesis is in keeping with previous data reported in the literature. Indeed, using CDs from candle soot that were functionalized to exhibit a negative, neutral or positive charge, Havrdova et al. (2016) showed that the positively charged CDs exhibited greater toxicity $\left(\mathrm{EC}_{50}\right.$ of ca. $50 \mu \mathrm{g} / \mathrm{mL}$ at $24 \mathrm{~h}$ ) compared to neutral and negative CDs (EC 50 of $300 \mu \mathrm{g} / \mathrm{mL}$ at $24 \mathrm{~h}$ ). Similarly, in a recent study conducted on the murine macrophage cell line RAW 264.7, negatively charged CDs were found to have limited toxicity (cell viability loss was less than $20 \%$ at concentration higher than $250 \mu \mathrm{g} / \mathrm{mL}$ ) (Lategan et al. 2018). The carbon source used to produce CDs could also impact their safety, as suggested in a very recent study (Cailotto et al. 2018). As well, the very small size of the NPs might also favor their biological reactivity, and thus their toxicological effects. At last, the mode of synthesis of CDs is another possible influencing factor. But, so far little is known on the role of these different factors in CD safety. A large-scale study comparing the safety of CDs produced from different reagents through different synthesis processes and exhibiting different physicochemical characteristics will be valuable to better understand the determinants of CD toxicity. In any event, our data and those of other groups support the idea that the biocompatibility of CDs cannot be generalized, and that toxicological properties of these NPs should be systematically evaluated.

\section{CD cell uptake and trafficking to the lysosome}

Thanks to their outstanding intrinsic fluorescence properties, CDs are extensively developed for bioimaging purposes and numerous studies have reported efficient cell uptake of these NPs by a variety of cell types (Edison et al. 2016; Qian et al. 2014; Ray et al. 2009; Yang et al. 2009). Investigating the transfection activity of PEI-based CDs, we showed internalization of CD-DNA 
complexes in airway epithelial cells, at a time point as early as $1 \mathrm{~h}$ (Pierrat et al. 2015). In the present study, cell uptake of the CDs alone was assessed in macrophages exposed to non cytotoxic concentrations of the NPs (6 or $12 \mu \mathrm{g} / \mathrm{mL}$ ) for 1 or $4 \mathrm{~h}$, using CLSM. To attest CD internalization, the cell membrane was labeled with the fluorescent probe DSQ12S (in green on figure 3), as described in a previous report (Pierrat et al. 2015). As shown on figures 3a to 3f, CD blue fluorescence was observed at $1 \mathrm{~h}$ after addition of CDs onto cells, at both NP concentrations (Fig. 3b and 3c), and the fluorescence signal clearly increased at $4 \mathrm{~h}$ (Fig. 3e and 3f). As shown on figure 3g, a quantitative analysis of the intracellular fluorescence confirmed an increase in CD uptake with time ( $<0.05$ at $4 \mathrm{~h})$ and NP concentration $(\mathrm{p}<0.05$ at $6 \mu \mathrm{g} / \mathrm{mL}$ and $\mathrm{p}<0.01$ at $12 \mu \mathrm{g} / \mathrm{mL}$ ). This time- and concentration-dependent uptake of CDs by cultured cells is in agreement with previous reports (Liu et al. 2012; Qian et al. 2014; Ray et al. 2009; Wu et al. 2017; Zhou et al. 2014). Surface charge is considered to have a great importance for cell uptake of NPs. Positively charged NPs tend to exhibit greater cell internalisation due to the attractive electrostatic interactions with negatively charged cell membranes (Sharifi et al. 2012). Thus, in the present study, CD uptake might be favored by the initial electrostatic anchorage of the cationic NPs to the cell surface. Besides, once in contact with biological fluids, most NPs are quickly covered by a layer of proteins or other biomolecules forming the so-called corona (Mahmoudi et al. 2011). This binding that correlates with NP surface charge regulates recognition and uptake of NPs by immune cells, particularly phagocytes such as macrophages (Aggarwal et al. 2009; Ritz et al. 2015). The formation of a protein corona on the surface of CDs was previously reported in the literature (Zhou et al. 2014). Thus, the formation of a protein corona around our cationic CDs can be considered as well as responsible for interaction of the NPs with the cell membrane and their subsequent cell internalization. This particular point needs further investigations.

Cell entry of NPs is known to involve several pathways, which almost all end up into the lysosomes (Zhao et al. 2011). To investigate trafficking of CDs into these organelles, cells were labeled with the LysoTracker ${ }^{\circledR}$ Red fluorescent probe before imaging. As shown on CLMS images of figure 4, blue fluorescence of CDs colocalized with the LysoTracker ${ }^{\circledR}$ Red staining, particularly at the 4-h incubation time. Quantitative analysis of the fluorescence intensity of both CDs and the LysoTracker ${ }^{\circledR}$ Red probe confirmed this colocalization at $1 \mathrm{~h} \mathrm{(Fig.} \mathrm{4g)} \mathrm{and} 4 \mathrm{~h}$ (Fig. 4h), with Pearson's correlation coefficients of 0.52 ( $\mathrm{CI}_{95}: 0.48$ to 0.59 ) and 0.54 ( $\mathrm{Cl}_{95}: 0.37$ to 0.65), respectively. Cell observation by TEM supported fluorescence data and showed the presence of CDs in the cytosol (Fig. 5a), and in particular in lysosome-like structures (Fig. 5b). Thus, we can assume that, after their uptake by macrophages, CDs accumulate in the acidic lysosomal compartment of the cells, most probably thanks to the amine groups displayed at the 
surface of the NPs. However, as it can be seen in figures $\mathbf{4 g}$ and $\mathbf{4 h}$, despite a massive proportion of CDs present in the lysosomes (76\% at $1 \mathrm{~h}$ and $80 \%$ at $4 \mathrm{~h}$ ), some CD fluorescence did not merge with the LysoTracker ${ }^{\circledR}$ Red signal, indicating that part of the CDs might have diffused out of the lysosomes. Our data are consistent with those obtained by Wu et al. on cationic PEI-based CDs developed as fluorescent probes for lysosomal imaging (Wu et al. 2017). Indeed, although these CDs were mainly localized into the organelles after their cell entry, some NP diffusion into the cytoplasm was observed.

\section{Oxidative stress and inflammation evoked by CDs}

Taking into account the cytotoxicity of the herein described CDs, underlining mechanisms were investigated. Oxidative stress is considered as one of the main mechanisms leading to NP cytotoxicity (Hussain et al. 2009; Marano et al. 2011). It results from an imbalance between production of reactive oxygen species (ROS) and levels of cell anti-oxidant agents, among which reduced glutathione (GSH). In the present study, exposure of cells to CDs (3-50 $\mu \mathrm{g} / \mathrm{mL}$ ) for $4 \mathrm{~h}$ resulted in a dose-dependent increase in ROS production with a 2.1 -fold increase at the highest NP concentration (Fig. 6a). This has to be interpreted with regard to the 5-fold increase of ROS evoked by $100 \mathrm{mM} \mathrm{H}_{2} \mathrm{O}_{2}$ (positive control). Consistent with ROS production, CDs induced a dosedependent decrease in cell GSH content, reaching almost $85 \%$ at $50 \mu \mathrm{g} / \mathrm{mL}$ (Fig. 6b). These data are in agreement with previous ones reported in fibroblasts in response to PEI-based CDs (Havrdova et al. 2016).

Since oxidative stress may trigger inflammation, we investigated a possible inflammatory effect of CDs by measuring secretion of the cytokine IL-8 by cells exposed to the NPs (3-50 $\mu \mathrm{g} / \mathrm{mL}$ ) for $24 \mathrm{~h}$. IL-8 is one of the main macrophage-derived inflammatory cytokines. Its expression is controlled by $\mathrm{NF}-\kappa \mathrm{B}$, which is a redox-sensitive transcription factor and is therefore increased in response to oxidative stress. As shown on figure $6 \mathrm{c}$, CDs induced a dosedependent increase in IL-8 secretion, up to the dose of $25 \mu \mathrm{g} / \mathrm{mL}$. At $50 \mu \mathrm{g} / \mathrm{mL}$, the cytokine secretion decreased, most probably as a consequence of an excessive loss in cell viability. This in vitro inflammatory response is in line with our previous in vivo data that showed some increase in the production of the murine IL-8 homologue, $\mathrm{KC}$, in the lung of mice treated with bPEI25kbased CDs complexed to DNA (Pierrat et al. 2015). To the best of our knowledge, only one study has evaluated so far the capacity of CDs to alter the production of inflammatory mediators, such as IL-8, in isolated immune cells (Lategan et al. 2018). This study showed that high concentrations of CDs upregulated several inflammatory biomarkers, among which IL-8 in the murine macrophage cell line, RAW 264.7, and in human whole blood cells. 
Involvement of the lysosome in the toxicological responses evoked by CDs

Trafficking to the lysosomes has been reported for NPs of various chemical compositions, including silver-, silica-, polystyrene- and carbon-based NPs, and has been associated with loss of lysosomal integrity (Schutz et al. 2016; Tahara et al. 2012; Wan et al. 2013; Xia et al. 2008). Thus, the ability of the CDs investigated herein to induce lysosomal permeabilization was assessed using the lysosomotropic dye neutral red (NR) (Repetto et al. 2008). At neutral pH, this weak cationic dye crosses the cell and lysosomal membranes by simple diffusion, and at acidic pH (i.e. in lysosomes) it binds to the membrane and accumulates. Thus, NR accumulation in cells decreases in case of lysosomal integrity loss. As shown in figure 7a, CDs induced a dosedependent decrease in cell NR staining. This decrease reached $50 \%$ at a CD concentration of $14.37 \mu \mathrm{g} / \mathrm{mL}\left(\mathrm{CI}_{95}: 10.95\right.$ to $18.87 \mu \mathrm{g} / \mathrm{mL}$ ), which is consistent with cell viability loss measured by MTT with an $\mathrm{EC}_{50}$ value of $14.38 \mu \mathrm{g} / \mathrm{mL}$ (Fig. 2). Although the mechanism of NP-induced lysosomal permeabilization is still unclear, a "proton sponge" effect has been suggested for cationic titratable NPs (Ma et al. 2011; Xia et al. 2008). Due to their high proton buffering ability, such NPs could interfere with lysosomal acidification, perturbating the proton pump responsible for a chloride influx, which results in osmotic swelling and, ultimately, in the rupture of the lysosomal membrane. In the present study, CDs were prepared from bPEI25k which contains primary, secondary and tertiary amine groups. These CDs are thus likely to evoke such a proton sponge effect.

Loss of integrity of the lysosomal membrane can induce mitochondrial dysfunction (Boya and Kroemer 2008; Repnik et al. 2014). In the present study, mitochondrial dysfunction in response to CDs was assessed by monitoring the change in mitochondrial membrane potential in cells treated or not with CDs (3-50 $\mu \mathrm{g} / \mathrm{mL}$ ) for $4 \mathrm{~h}$, using the JC-10 probe. A dose-dependent change in mitochondrial membrane potential was observed in response to CDs (Fig. 7b). The mitochondrial dysfunction induced by $50 \mu \mathrm{g} / \mathrm{mL}$ CDs, reaching an almost 6 -fold increase when compared to control, was comparable to the one reported in the literature for other types of NPs, such as CdSe:ZnS quantum dots (Manshian et al. 2015).

NLRP3 inflammasome activation is another possible consequence of lysosomal permeabilization (Boya and Kroemer 2008; Repnik et al. 2014). Inflammasomes are cytosolic multiprotein complexes classically composed of a sensor protein of the NOD-like receptor (NLR) family, the adaptor protein ASC, and the cysteine protease caspase-1, as a downstream effector. They are assembled and activated in response to endogenous or exogenous danger signals and have a key role in the host defense. Among inflammasomes, the NLRP3 inflammasome is 
responsible for the maturation of the cytokines IL-1 $\beta$ and IL-18 upon cleavage by caspase-1. These maturated cytokines are involved in the generation and regulation of systemic and local responses to infection and injury. Several kinds of NPs have been reported to activate the NLRP3 inflammasome (Dostert et al. 2008; Peeters et al. 2014), but whether CDs may activate this pathways remains unknown. To highlight NLRP3 inflammasome activation in response to CDs, the cytokine IL-1 $\beta$ was measured in the culture supernatant of cells treated or not with the caspase-1 inhibitor Z-WEHD and subsequently exposed to CDs (3-50 $\mu \mathrm{g} / \mathrm{mL}$ ) for $4 \mathrm{~h}$. As shown on figure 7c, cell exposure to CDs resulted in a dose-dependent secretion of IL-1 $\beta$ that was almost totally inhibited in the presence of the caspase-1 inhibitor, thus confirming NLRP3 inflammasome activation by CDs. The IL- $1 \beta$ secretion induced by $25 \mu \mathrm{g} / \mathrm{mL}$ CDs was comparable to the one evoked by $0.1 \mu \mathrm{g} / \mathrm{mL}$ bacterial lipopolysaccharides (LPS), a well-known inflammasome inducer (data not shown). Thus, like other NPs (Dostert et al. 2008; Peeters et al. 2014), CDs investigated herein can induce NLRP3 inflammasome activation.

The lysosomal protease cathepsin B is one of the most important effector of toxicological responses resulting from lysosomal damage (Boya and Kroemer 2008). To confirm the role of lysosomes in the cellular responses evoked by CDs, we assessed the effect of the cathepsin B inhibitor CA-074Me on CD-induced changes in mitochondrial membrane potential and IL-1 $\beta$ secretion. It was found that the cathepsin B inhibitor significantly reduced both the changes in mitochondrial membrane potential (Fig. 7d) and the IL-1 $\beta$ secretion (Fig. 7e) induced by a 4-h incubation of the cells with CDs $(6,12$ or $25 \mu \mathrm{g} / \mathrm{mL})$. These data confirmed the implication of the lysosome in the cytotoxicity evoked by bPEI25k-based CDs, providing for the first time a mechanistic pathway for the toxicological effects of these cationic CDs in immune cells. 


\section{Conclusion}

We characterized the cell uptake and trafficking, and the toxicological properties of bPEI25kbased cationic CDs in macrophages, and investigated the implication of the lysosome in these responses. CDs were rapidly internalized by cells and localized into the lysosomes after their cell entry. The NPs induced a dose- and time-dependent loss in cell viability that was associated with induction of an oxidative stress and IL-8 release. The CDs triggered also some loss in lysosome integrity, mitochondrial dysfunction and NLRP3 inflammasome activation. Inhibition of the lysosomal protease cathepsin B significantly reduced CD-induced mitochondrial dysfunction and NLRP3 inflammasome activation, confirming implication of the lysosome in the toxicological effects of the NPs. Our study thus supports the idea that biocompatibility of CDs can not be generalized, and that toxicological properties of new NPs, particularly positively-charged ones, should be systematically evaluated. It provides for the first time a mechanistic pathway for the toxicological effects of cationic bPEI25k-based CDs. Taking into account the potential of cationic CDs as nucleic acid carriers for gene therapy, the present data emphasize the necessity to develop strategies to improve biocompatibility of these nanocarriers, while preserving their gene delivery properties. 


\section{Acknowledgement}

This work was supported by the agence nationale de sécurité sanitaire de l'alimentation, de l'environnement et du travail (ANSES - Grant n EST-2015/1/005). 


\section{Figure legends}

Fig. 1. Characteristics of CDs. (A) Representative TEM image of the CDs. Scale bar: $100 \mathrm{~nm}$. (B) CD size distribution from DLS measurements. (C) ${ }^{1} \mathrm{H}$ - and (D) ${ }^{13} \mathrm{C}$-NMR spectra of bPEI25k, citric acid and CDs in deuterated water ( $\boldsymbol{\nabla}$ ), with $t$-butyl alcohol as an internal reference (*). (E) FTIR spectra of bPEI25k, citric acid and CDs. (F) UV-Vis absorption spectrum (black line) and excitation wavelength-independent emission spectra of CDs (excitation from 300 to $400 \mathrm{~nm}$ ).

Fig. 2. Effect of CDs on cell viability. MTT assay in cells treated for 1,4 , and $24 \mathrm{~h}$ with increasing concentrations of the CDs. Results are means \pm SEM of $n=3$ to 9 experiments. They were expressed in percentage of controls, as described in the Material and Methods section.

Fig. 3. Cell uptake of CDs. (A-F) CLSM images of cells untreated (A and D) or treated with 6 (B and $\mathbf{E}$ ) or $12 \mu \mathrm{g} / \mathrm{mL}$ (C and F) CDs for $1 \mathrm{~h} \mathrm{(A,} \mathrm{B} \mathrm{and} \mathrm{C)} \mathrm{or} 4 \mathrm{~h}$ (D, E and F) and stained with the fluorescent membrane probe DSQ12S. The cell membrane is colored in green and CDs appeared in blue. All scale bars: $10 \mu \mathrm{m}$. (G) Quantification of internalization per cell as a function of CD concentration and incubation time. Results are means \pm SEM of at least 200 cells from $n=2$ or 3 biological replicates. ${ }^{*} \mathrm{p}<0.05$ when comparing CD internalization in function of concentration at $4 \mathrm{~h} ; \# \mathrm{p}<0.05$ and ${ }^{\#} \mathrm{p}<0.01$ when comparing CD internalization as a function of time at a given concentration.

Fig. 4. Colocalization of CDs with lysosomes. (A-F) CLSM images of cells treated with 12 $\mu \mathrm{g} / \mathrm{mL}$ CDs for $1 \mathrm{~h}(\mathbf{A}, \mathbf{B}$ and $\mathbf{C})$ or $4 \mathrm{~h}(\mathbf{D}, \mathbf{E}$ and $\mathbf{F})$ and stained with the LysoTracker ${ }^{\circledR}$ Red. (A and D): CDs; (B and E): LysoTracker ${ }^{\circledR} \operatorname{Red}$; (C and F): merged. All scale bars: $10 \mu \mathrm{m}$. (G and $\left.\mathbf{H}\right)$ : Colocalization quantitative analysis at $\mathrm{t}=1 \mathrm{~h}(\mathbf{G})$ and $\mathrm{t}=4 \mathrm{~h}(\mathbf{H})$.

Fig. 5. Representative TEM images of cells treated with $12 \mu \mathrm{g} / \mathrm{mL}$ CDs for $4 \mathrm{~h}$. Scale bar: $2 \mu \mathrm{m}$ (A) or $500 \mathrm{~nm}$ (B). Red arrow: CDs; yellow circle: lysosome (Ly).

Fig. 6. Oxidative stress and inflammation evoked by CDs. (A) ROS production and (B) reduced GSH content in cells exposed for $4 \mathrm{~h}$ to increasing concentrations of the CDs or to 100 
$\mathrm{mM} \mathrm{H}_{2} \mathrm{O}_{2}$. Results are means \pm SEM of $\mathrm{n}=1$ to 4 experiments. They were expressed in percentage of control (ROS) or as absolute values (GSH), as described in the Material and Methods section. ${ }^{*} \mathrm{p}<0.05,{ }^{* *} \mathrm{p}<0.01$, and ${ }^{* * *} \mathrm{p}<0.001$, when compared to untreated cells. (C) Secretion of the inflammatory cytokine IL-8 in the culture medium of cells exposed to increasing concentrations of CDs for $24 \mathrm{~h}$. Results are means \pm SEM of $n=3$ experiments. ${ }^{*} p<0.05,{ }^{* *} p<0.01$, and ${ }^{* * *} \mathrm{p}<0.001$, when compared to cytokine secretion in absence of CDs.

Fig. 7. Involvement of the lysosome in the cellular responses evoked by CDs. (A) NR assay in cells treated for $24 \mathrm{~h}$ with increasing concentrations of the CDs. Results are means \pm SEM of $\mathrm{n}=3$ experiments. They were expressed in percentage of controls, as described in the Material and Methods section. ${ }^{* * *} \mathrm{p}<0.001$, when compared to untreated cells. (B) Mitochondrial membrane potential (MMP) measured in cells treated for $4 \mathrm{~h}$ with increasing concentrations of CDs, using the JC-10 probe. Data represents the mean \pm SEM of $n=5$ experiments. ${ }^{*} \mathrm{p}<0.05$ and ${ }^{* * *} \mathrm{p}<0.001$, when compared to untreated cells. (C) IL-1 $\beta$ measured in the culture supernatant of cells pre-treated (grey bars) or not (black bars) with the caspase-1 inhibitor Z-WEHD and incubated for $4 \mathrm{~h}$ with increasing concentrations of CDs. Data represents the mean \pm SEM of $\mathrm{n}=3$ experiments. ${ }^{* * *} \mathrm{p}<0.001$, when compared to untreated cells (no CDs and no inhibitor); \#\#\# $<0.001$, when compared to cells pre-treated with the caspase- 1 inhibitor. (D) MMP measured in cells and (E) IL-1 $\beta$ measured in the culture supernatant of cells pre-treated (grey bars) or not (black bars) with the cathepsin B inhibitor CA-074Me and incubated for $4 \mathrm{~h}$ with increasing concentrations of CDs, as described in the Material and Methods section. Data represents the mean \pm SEM of $\mathrm{n}=3$ experiments. ${ }^{* *} \mathrm{p}<0.01$ and ${ }^{* * *} \mathrm{p}<0.001$, when compared to untreated cells (no CD and no inhibitor); ${ }^{\#} \mathrm{p}<0.05$ and ${ }^{\#} \mathrm{p}<0.01$, when compared to cells pretreated with the cathepsin B inhibitor. 
Conflict of Interest : The authors declare that they have no conflict of interest. 


\section{References}

Aggarwal P, Hall JB, McLeland CB, Dobrovolskaia MA, McNeil SE (2009) Nanoparticle interaction with plasma proteins as it relates to particle biodistribution, biocompatibility and therapeutic efficacy. Adv Drug Deliv Rev 61:428-437.

Blas-Garcia A, Baldovi HG, Polo M, Victor VM, Garcia H, Herance JR (2016) Toxicological properties of two fluorescent carbon quantum dots with onion ring morphology and their usefulness as bioimaging agents. RSC Adv 6:30611-30622.

Boussif O, Lezoualch F, Zanta MA, Mergny MD, Scherman D, Demeneix B, Behr JP (1995) A versatile vector for gene and oligonucleotide transfer into cells in culture and in-vivo: polyethylenimine. Proc Natl Acad Sci USA 92:7297-7301.

Boya P, Kroemer G (2008) Lysosomal membrane permeabilization in cell death. Oncogene 27:6434-6451.

Cailotto S, Amadio E, Facchin M, Selva M, Pontoglio E, Rizzolio F, Riello P, Toffoli G, Benedetti A, Perosa A (2018) Carbon dots from sugars and ascorbic acid: Role of the precursors on morphology, properties, toxicity, and drug uptake. ACS Med Chem Lett 9:832-837.

Cao X Cao X, Wang J, Deng W, Chen J, Wang Y, Zhou J, Du P, Xu W, Wang Q, Wang Q, Yu Q, Spector M, Yu J, Xu X (2018) Photoluminescent cationic carbon dots as efficient non-viral delivery of plasmid SOX9 and chondrogenesis of fibroblasts. Sci Rep 8(1):7057.

Cayuela A, Soriano ML, Carrillo-Carrion C, Valcarcel M (2016) Semiconductor and carbon-based fluorescent nanodots: the need for consistency. Chem Commun 52:1311-1326.

Collot M, Kreder R, Tatarets AL, Patsenker LD, Mely Y, Klymchenko AS (2015) Bright fluorogenic squaraines with tuned cell entry for selective imaging of plasma membrane vs. endoplasmic reticulum. Chem Commun 51:17136-17139.

Das SK, Liu YY, Yeom S, Kim DY, Richards CI (2014) Single-particle fluorescence intensity fluctuations of carbon nanodots. Nano Lett 14:620-625.

Dostert C, Petrilli V, Van Bruggen R, Steele C, Mossman BT, Tschopp J (2008) Innate immune activation through Nalp3 inflammasome sensing of asbestos and silica. Science 320:674-677.

Dou Q, Fang X, Jiang S, Chee PL, Lee T-C, Loh XJ (2015) Multi-functional fluorescent carbon dots with antibacterial and gene delivery properties. RSC Adv 5:46817-46822. 
Edelstein AD, Tsuchida MA, Amodaj N, Pinkard H, Vale RD, Stuurman N (2014) Advanced methods of microscope control using $\mu$ Manager software. J Biol Methods 1(2):e10.

Edison TNJI, Atchudan R, Sethuraman MG, Shim JJ, Lee YR (2016) Microwave assisted green synthesis of fluorescent $\mathrm{N}$-doped carbon dots: Cytotoxicity and bio-imaging applications. J Photochem Photobiol B 161:154-161.

El Badawy AM, Silva RG, Morris B, Scheckel KG, Suidan MT, Tolaymat TM (2011) Surface chargedependent toxicity of silver nanoparticles. Environ Sci Technol 45:283-287.

Emam AN, Loutfy SA, Mostafa AA, Awad H, Mohamed MB (2017) Cytotoxicity, biocompatibility and cellular response of carbon dots-plasmonic based nano-hybrids for bioimaging. RSC Adv $7: 23502-23514$.

Gomez IJ, Arnaiz B, Cacioppo M, Arcudi F, Prato M (2018) Nitrogen-doped carbon nanodots for bioimaging and delivery of paclitaxel. J Mater Chem B 6:5540-5548.

Hao AJ, Guo XJ, Wu Q, Sun Y, Cong CR, Liu WJ (2016) Exploring the interactions between polyethyleneimine modified fluorescent carbon dots and bovine serum albumin by spectroscopic methods. J Lumines 170:90-96.

Havrdova M, Hola K, Skopalik J, Tomankova K, Martin PA, Cepe K, Polakova K, Tucek J, Bourlinos $A B$, Zboril R (2016) Toxicity of carbon dots - Effect of surface functionalization on the cell viability, reactive oxygen species generation and cell cycle. Carbon 99:238-248.

Himaja AL, Karthik PS, Singh SP (2015) Carbon dots: the newest member of the carbon nanomaterials family. Chem Rec 15:595-615.

Hosseinkhani H (2006) DNA nanoparticles for gene delivery to cells and tissue. Int J Nanotechnol 3:416-461.

Hou XF, Hu Y, Wang P, Yang LJ, Al Awak MM, Tang YG, Twara FK, Qian HJ, Sun YP (2017) Modified facile synthesis for quantitatively fluorescent carbon dots. Carbon 122:389-394.

Hu LM, Sun Y, Li SL, Wang XL, Hu KL, Wang LR, Liang XJ, Wu Y (2014) Multifunctional carbon dots with high quantum yield for imaging and gene delivery. Carbon 67:508-513.

Hussain S, Boland S, Baeza-Squiban A, Hamel R, Thomassen LC, Martens JA, Billon-Galland MA, Fleury-Feith J, Moisan F, Pairon JC, Marano F (2009) Oxidative stress and proinflammatory effects of carbon black and titanium dioxide nanoparticles: Role of particle surface area and internalized amount. Toxicology 260:142-149. 
Jiang CK, Wu H, Song XJ, Ma XJ, Wang JH, Tan MQ (2014) Presence of photoluminescent carbon dots in Nescafe ${ }^{\circledR}$ original instant coffee: Applications to bioimaging. Talanta 127:68-74.

Kim J, Chankeshwara SV, Thielbeer F, Jeong J, Donaldson K, Bradley M, Cho WS (2016) Surface charge determines the lung inflammogenicity: A study with polystyrene nanoparticles. Nanotoxicology 10:94-101.

Kim S, Choi Y, Park G, Won C, Park YJ, Lee Y, Kim BS, Min DH (2017) Highly efficient gene silencing and bioimaging based on fluorescent carbon dots in vitro and in vivo. Nano Res 10:503-519.

Kundu A, Lee J, Park B, Ray C, Sankar KV, Kim WS, Lee SH, Cho IJ, Jun SC (2018) Facile approach to synthesize highly fluorescent multicolor emissive carbon dots via surface functionalization for cellular imaging. J Colloid Interface Sci 513:505-514.

Kwon W, Lee G, Do S, Joo T, Rhee SW (2014) Size-controlled soft-template synthesis of carbon nanodots toward versatile photoactive materials. Small 10:506-513.

Lategan K, Alghadi H, Bayati M, de Cortalezzi MF, Pool E (2018) Effects of graphene oxide nanoparticles on the immune system biomarkers produced by RAW 264.7 and human whole blood cell cultures. Nanomaterials (Basel) 8(2):125.

Li R, Wang X, Ji Z, Sun B, Zhang H, Chang CH, Lin S, Meng H, Liao YP, Wang M, Li Z, Hwang AA, Song TB, Xu R, Yang Y, Zink JI, Nel AE, Xia T (2013) Surface charge and cellular processing of covalently functionalized multiwall carbon nanotubes determine pulmonary toxicity. ACS Nano 7:2352-2368.

Li S, Guo Z, Zhang Y, Xue W, Liu ZH (2015) Blood compatibility evaluations of fluorescent carbon dots. ACS Appl Mater Interfaces 7:19153-19162.

Liu C, Zhang P, Zhai X, Tian F, Li W, Yang J, Liu Y, Wang H, Wang W, Liu W (2012) Nano-carrier for gene delivery and bioimaging based on carbon dots with PEI-passivation enhanced fluorescence. Biomaterials 33:3604-3613.

Liu H, Ye T, Mao C (2007) Fluorescent carbon nanoparticles derived from candle soot. Angew Chem Int Ed 46(34):6473-6475.

Ma X, Wu Y, Jin S, Tian Y, Zhang X, Zhao Y, Yu L, Liang XJ (2011) Gold nanoparticles induce autophagosome accumulation through size-dependent nanoparticle uptake and lysosome impairment. ACS Nano 5:8629-8639. 
Mahmoudi M, Lynch I, Ejtehadi MR, Monopoli MP, Bombelli FB, Laurent S (2011) Proteinnanoparticle interactions: Opportunities and challenges. Chem Rev 111(9):5610-5637.

Manshian BB, Soenen SJ, Al-Ali A, Brown A, Hondow N, Wills J, Jenkins GJ, Doak SH (2015) Cell type-dependent changes in $\mathrm{CdSe} / \mathrm{ZnS}$ quantum dot uptake and toxic endpoints. Toxicol Sci 144:246-258.

Marano F, Hussain S, Rodrigues-Lima F, Baeza-Squiban A, Boland S (2011) Nanoparticles: Molecular targets and cell signalling. Arch Toxicol 85:733-741.

Marega R, Aroulmoji V, Dinon F, Vaccari L, Giordani S, Bianco A, Murano E, Prato M (2009) Diffusion-ordered NMR spectroscopy in the structural characterization of functionalized carbon nanotubes. J Am Chem Soc 131:9086-9093.

Nel A, Xia T, Madler L, Li N (2006) Toxic potential of materials at the nanolevel. Science 311:622627.

Peeters PM, Eurlings IM, Perkins TN, Wouters EF, Schins RP, Borm PJ, Drommer W, Reynaert NL, Albrecht C (2014) Silica-induced NLRP3 inflammasome activation in vitro and in rat lungs. Part Fibre Toxicol 11:58.

Pierrat P, Wang R, Kereselidze D, Lux M, Didier P, Kichler A, Pons F, Lebeau L (2015) Efficient in vitro and in vivo pulmonary delivery of nucleic acid by carbon dot-based nanocarriers. Biomaterials 51:290-302.

Pretsch E, Bühlmann P, Affolter C (2000) Structure determination of organic compounds. 3rd edn. Springer-Verlag, Berlin Heidelberg.

Qian J, Chen J, Ruan S, Shen S, He Q, Jiang X, Zhu J, Gao H (2014) Preparation and biological evaluation of photoluminescent carbonaceous nanospheres. J Colloid Interface Sci 429:77-82.

Ray SC, Saha A, Jana NR, Sarkar R (2009) Fluorescent carbon nanoparticles: synthesis, characterization, and bioimaging application. J Phys Chem C 113:18546-18551.

Repetto G, del Peso A, Zurita JL (2008) Neutral red uptake assay for the estimation of cell viability/cytotoxicity. Nat Protoc 3(7):1125-1131.

Repnik U, Hafner Cesen M, Turk B (2014) Lysosomal membrane permeabilization in cell death: concepts and challenges. Mitochondrion 19:49-57.

Ritz S, Schöttler S, Kotman N, Baier G, Musyanovych A, Kuharev J, Landfester K, Schild H, Jahn O, Tenzer S, Mailänder V (2015) Protein corona of nanoparticles: Distinct proteins regulate the cellular uptake. Biomacromolecules 16(4):1311-1321. 
Ronzani C, Spiegelhalter C, Vonesch JL, Lebeau L, Pons F (2012) Lung deposition and toxicological responses evoked by multi-walled carbon nanotubes dispersed in a synthetic lung surfactant in the mouse. Arch Toxicol 86:137-149.

Sachdev A, Matai I, Gopinath P (2014) Implications of surface passivation on physicochemical and bioimaging properties of carbon dots. RSC Adv 4:20915-20921.

Salieri B, Pasteris A, Netkueakul W, Hischier R (2017) Key physicochemical properties of nanomaterials in view of their toxicity: An exploratory systematic investigation for the example of carbon-based nanomaterial. J Nanopart Res 19(3):116.

Schütz I, Lopez-Hernandez T, Gao Q, Puchkov D, Jabs S, Nordmeyer D, Schmudde M, Rühl E, Graf CM, Haucke V (2016) Lysosomal dysfunction caused by cellular accumulation of silica nanoparticles. J Biol Chem 291:14170-14184.

Shahbazi MA, Hamidi M, Mäkilä EM, Zhang H, Almeida PV, Kaasalainen M, Salonen JJ, Hirvonen JT, Santos HA (2013) The mechanisms of surface chemistry effects of mesoporous silicon nanoparticles on immunotoxicity and biocompatibility. Biomaterials 34:7776-7789.

Sharifi S, Behzadi S, Laurent S, Forrest ML, Stroeve P, Mahmoudi M (2012) Toxicity of nanomaterials. Chem Soc Rev 41(6):2323-2343.

Sk MP, Jaiswal A, Paul A, Ghosh SS, Chattopadhyay A (2012) Presence of amorphous carbon nanoparticles in food caramels. Sci Rep 2:383.

Stefanakis D, Philippidis A, Sygellou L, Filippidis G, Ghanotakis D, Anglos D (2014) Synthesis of fluorescent carbon dots by a microwave heating process: structural characterization and cell imaging applications. J Nanopart Res 16(10):2646.

Stern ST, Adiseshaiah PP, Crist RM (2012) Autophagy and lysosomal dysfunction as emerging mechanisms of nanomaterial toxicity. Part Fibre Toxicol 9:20.

Tahara Y, Nakamura M, Yang M, Zhang M, Iijima S, Yudasaka M (2012) Lysosomal membrane destabilization induced by high accumulation of single-walled carbon nanohorns in murine macrophage RAW 264.7. Biomaterials 33:2762-2769.

Terrill RH, Postlethwaite TA Chen $\mathrm{CH}$, Poon CD, Terzis A, Chen AD, Hutchison JE, Clark MR, Wignall G, Londono JD, Superfine R, Falvo M, Johnson CS, Samulski ET, Murray RW (1995) Monolayers in three dimensions: NMR, SAXS, thermal, and electron hopping studies of alkanethiol stabilized gold clusters. J Am Chem Soc 117:12537-12548. 
Tian RX, Hu SL, Wu LL, Chang Q, Yang JL, Liu J (2014) Tailoring surface groups of carbon quantum dots to improve photoluminescence behaviors. Appl Surf Sci 301:156-160.

Wan B, Wang ZX, Lv QY, Dong PX, Zhao LX, Yang Y, Guo LH (2013) Single-walled carbon nanotubes and graphene oxides induce autophagosome accumulation and lysosome impairment in primarily cultured murine peritoneal macrophages. Toxicol Lett 221:118-127.

Wang JL, Qiu JJ (2016) A review of carbon dots in biological applications. J Mater Sci 51:47284738.

Wang K, Gao ZC, Gao G, Wo Y, Wang YX, Shen GX, Cui DX (2013) Systematic safety evaluation on photoluminescent carbon dots. Nanoscale Res Lett 8:122.

Wang L, Wang X, Bhirde A, Cao J, Zeng Y, Huang X, Sun Y, Liu G, Chen X (2014) Carbon-dot-based two-photon visible nanocarriers for safe and highly efficient delivery of siRNA and DNA. Adv Healthc Mater 3:1203-1209.

Wang Y, Anilkumar P, Cao L, Liu JH, Luo PG, Tackett KN 2nd, Sahu S, Wang P, Wang X, Sun YP (2011) Carbon dots of different composition and surface functionalization: cytotoxicity issues relevant to fluorescence cell imaging. Exp Biol Med 236:1231-1238.

Wu LL, Li XL, Ling YF, Huang CS, Jia NQ (2017) Morpholine derivative-functionalized carbon dots-based fluorescent probe for highly selective lysosomal imaging in living cells. ACS Appl Mater Interfaces 9:28222-28232.

Xia T, Kovochich M, Liong M, Zink JI, Nel AE (2008) Cationic polystyrene nanosphere toxicity depends on cell-specific endocytic and mitochondrial injury pathways. ACS Nano 2:85-96.

Xu XY, Ray R, Gu YL, Ploehn HJ, Gearheart L, Raker K, Scrivens WA (2004) Electrophoretic analysis and purification of fluorescent single-walled carbon nanotube fragments. J Am Chem Soc 126:12736-12737.

Yang ST, Wang X, Wang H, Lu F, Luo PG, Cao L, Meziani MJ, Liu JH, Liu Y, Chen M, Huang Y, Sun YP (2009) Carbon dots as nontoxic and high-performance fluorescence imaging agents. J Phys Chem C 113:18110-18114.

Yang X, Wang Y, Shen X, Su C, Yang J, Piao M, Jia F, Gao G, Zhang L, Lin Q (2017) One-step synthesis of photoluminescent carbon dots with excitation independent emission for selective bioimaging and gene delivery. J Colloid Interface Sci 492:1-7. 
Yuan Y, Guo B, Hao L, Liu N, Lin Y, Guo W, Li X, Gu B (2017) Doxorubicin-loaded environmentally friendly carbon dots as a novel drug delivery system for nucleus targeted cancer therapy. Colloids Surf B 159:349-359.

Zhang X, Wang Y, Liu W, Liang X, Si B, Liu E, Hu E, Fan J (2017) Facile preparation of surface functional carbon dots and their application in doxorubicin hydrochloride delivery. Mater Lett 209:360-364.

Zhao F, Zhao Y, Liu Y, Chang X, Chen C, Zhao Y (2011) Cellular uptake, intracellular trafficking, and cytotoxicity of nanomaterials. Small 7:1322-1337.

Zhou N, Zhu SJ, Maharjan S, Hao ZY, Song YB, Zhao XH, Jiang YF, Yang B, Lu LJ (2014) Elucidating the endocytosis, intracellular trafficking, and exocytosis of carbon dots in neural cells. RSC Adv 4:62086-62095. 


\section{Figure 1}
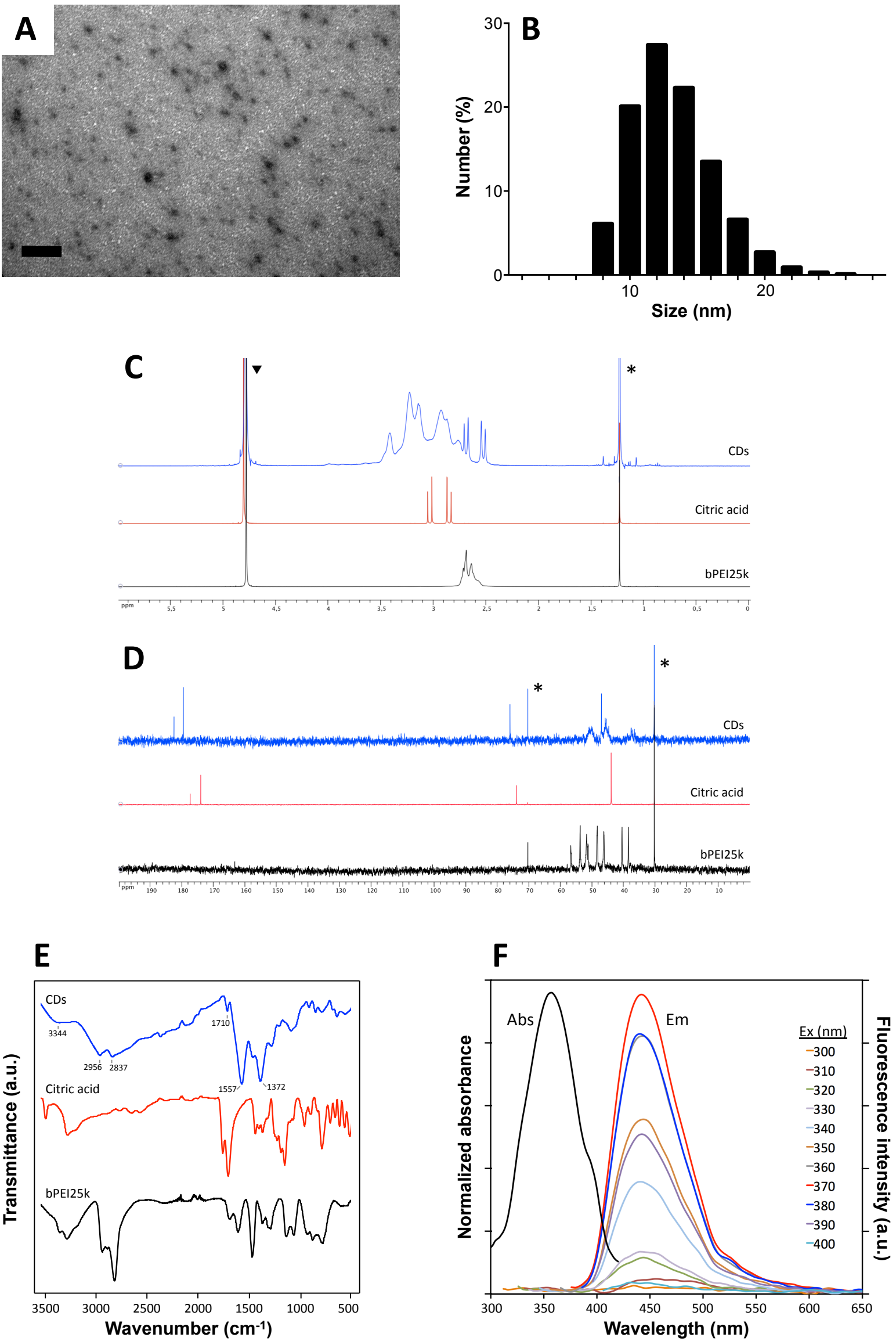
Figure 2

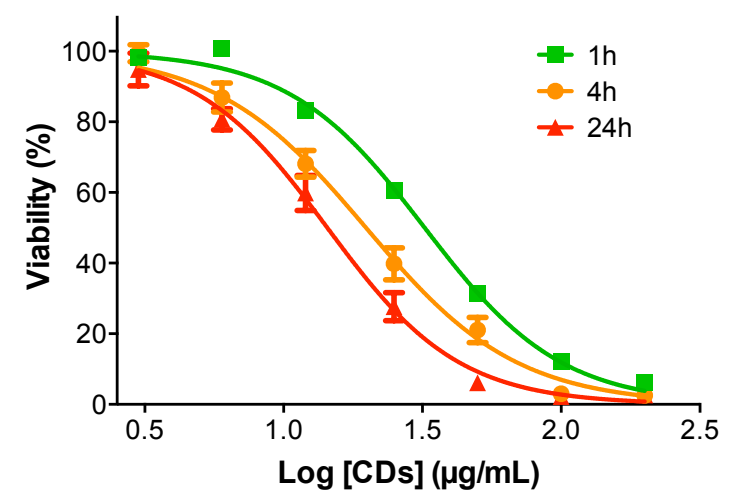


Figure 3
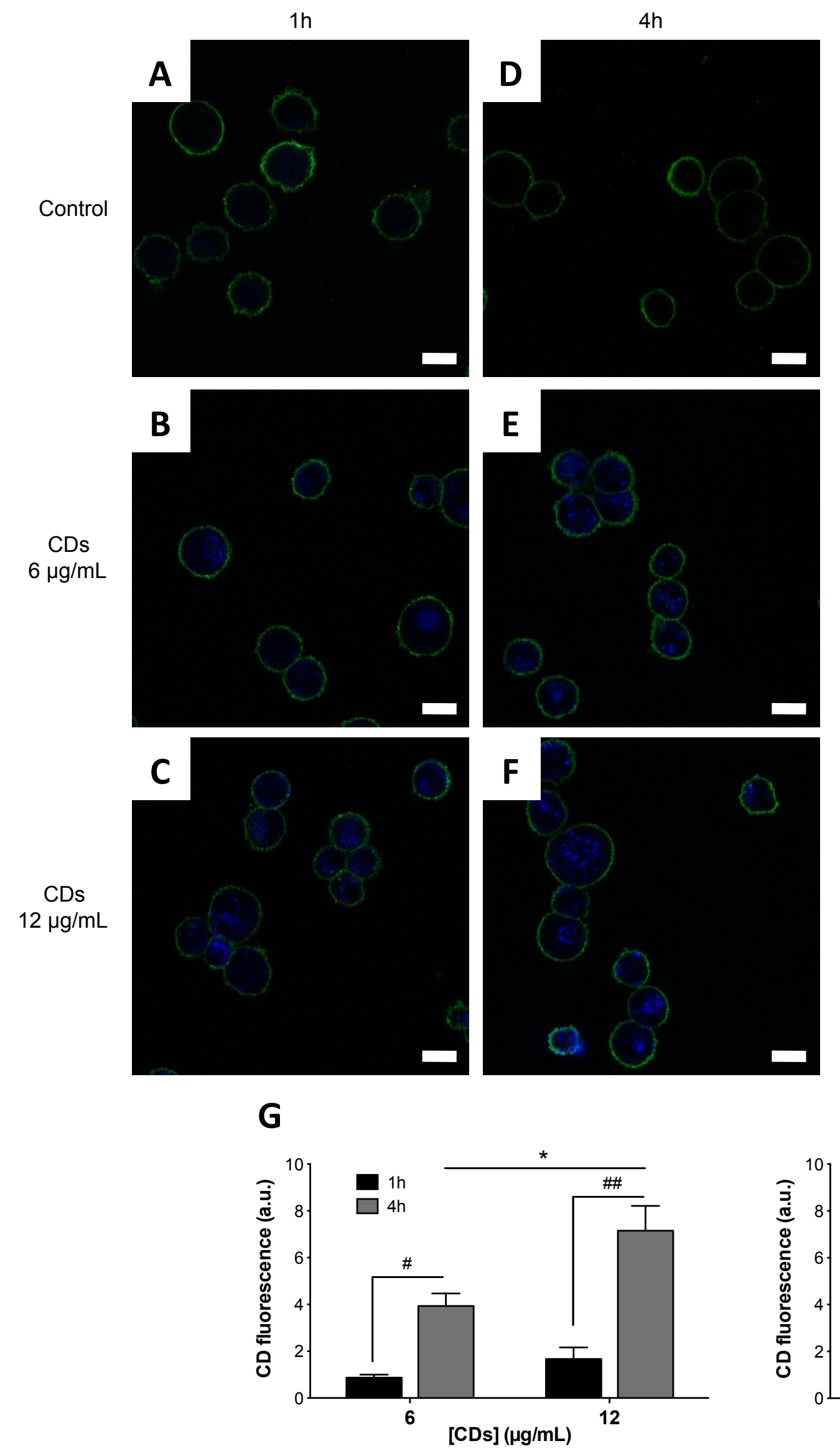
Figure 4
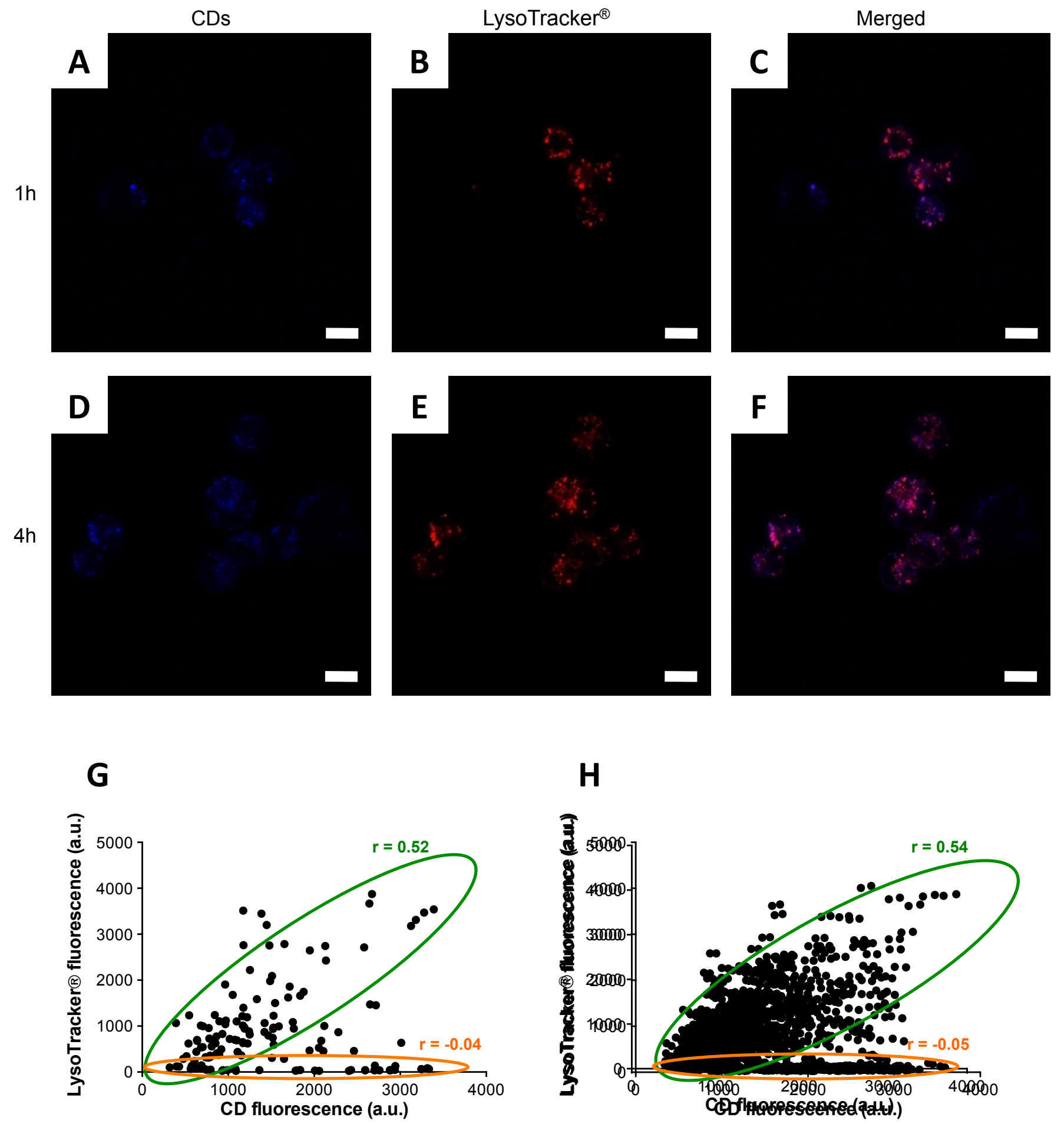
Figure 5
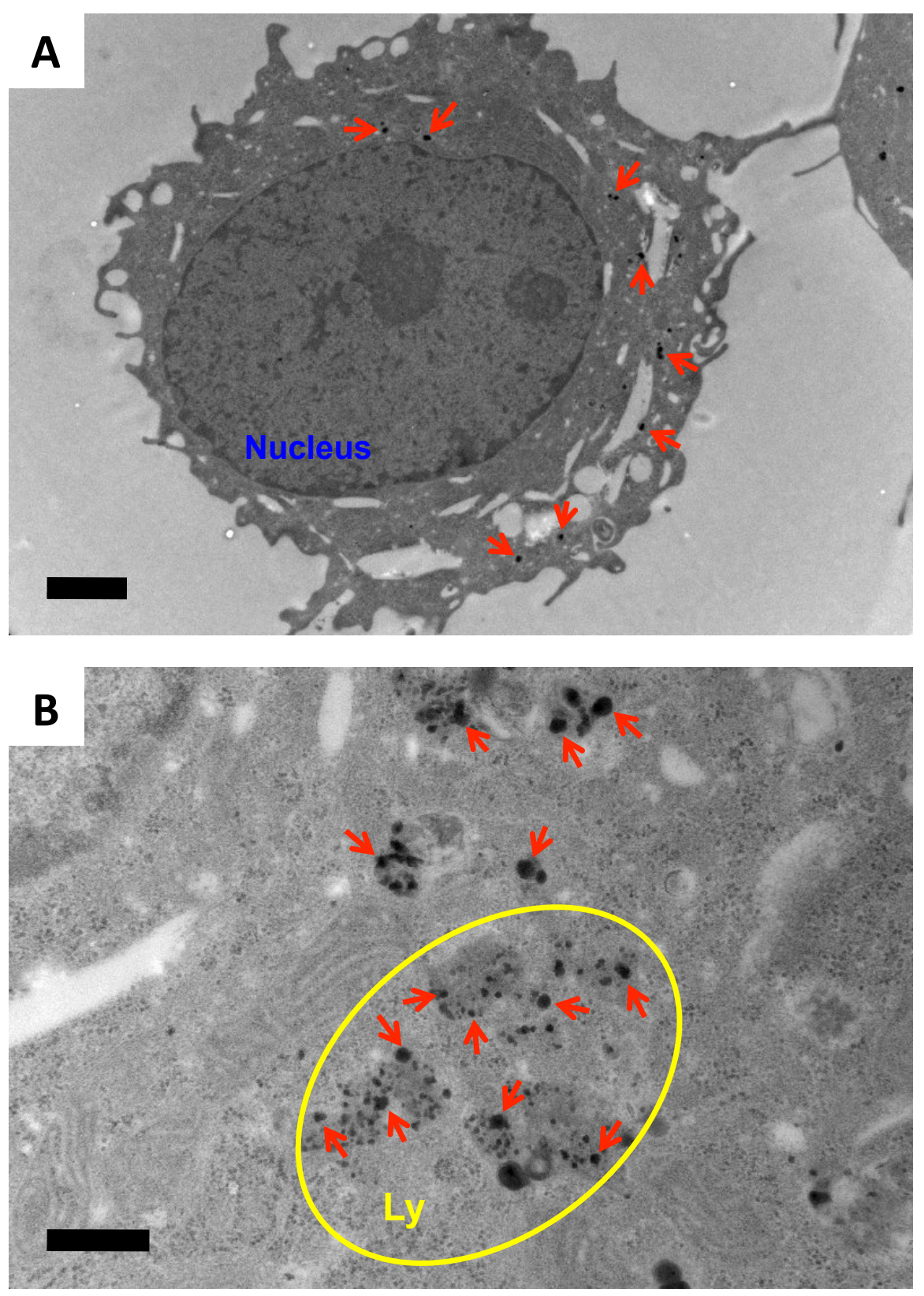
Figure 6
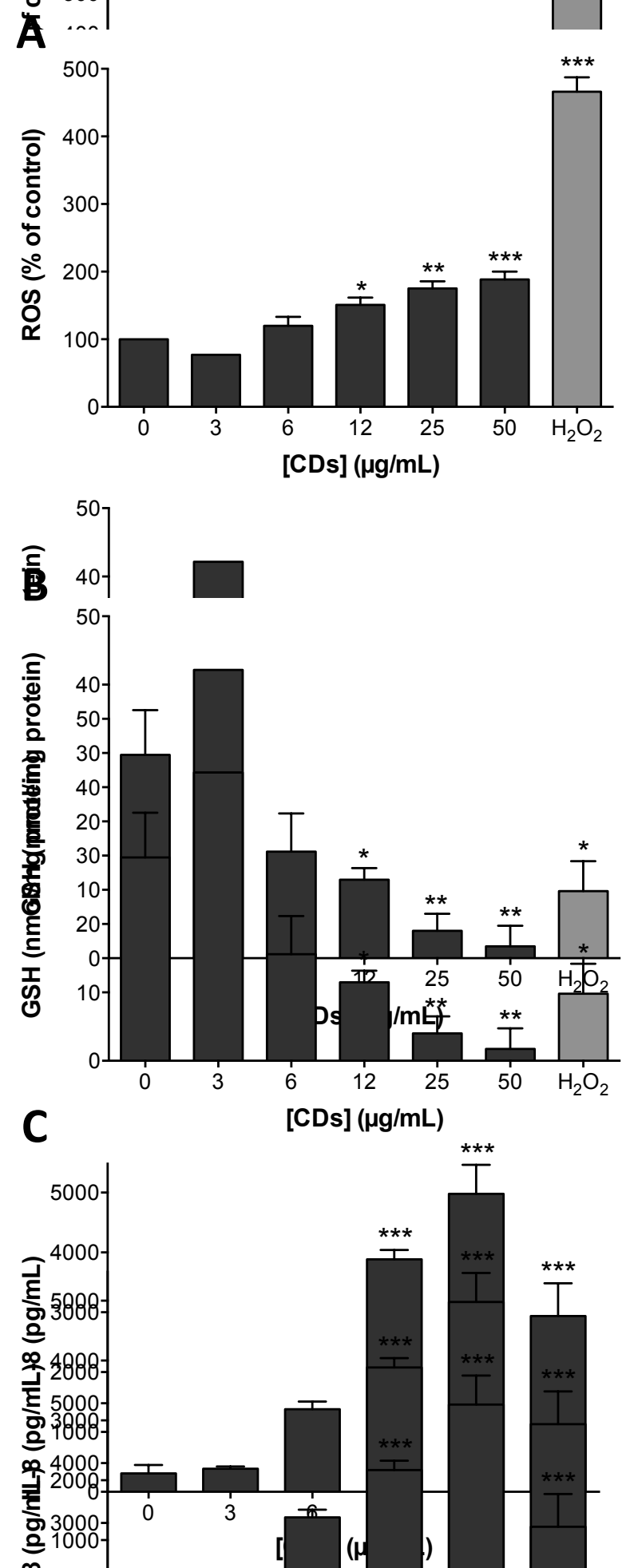
Figure 7
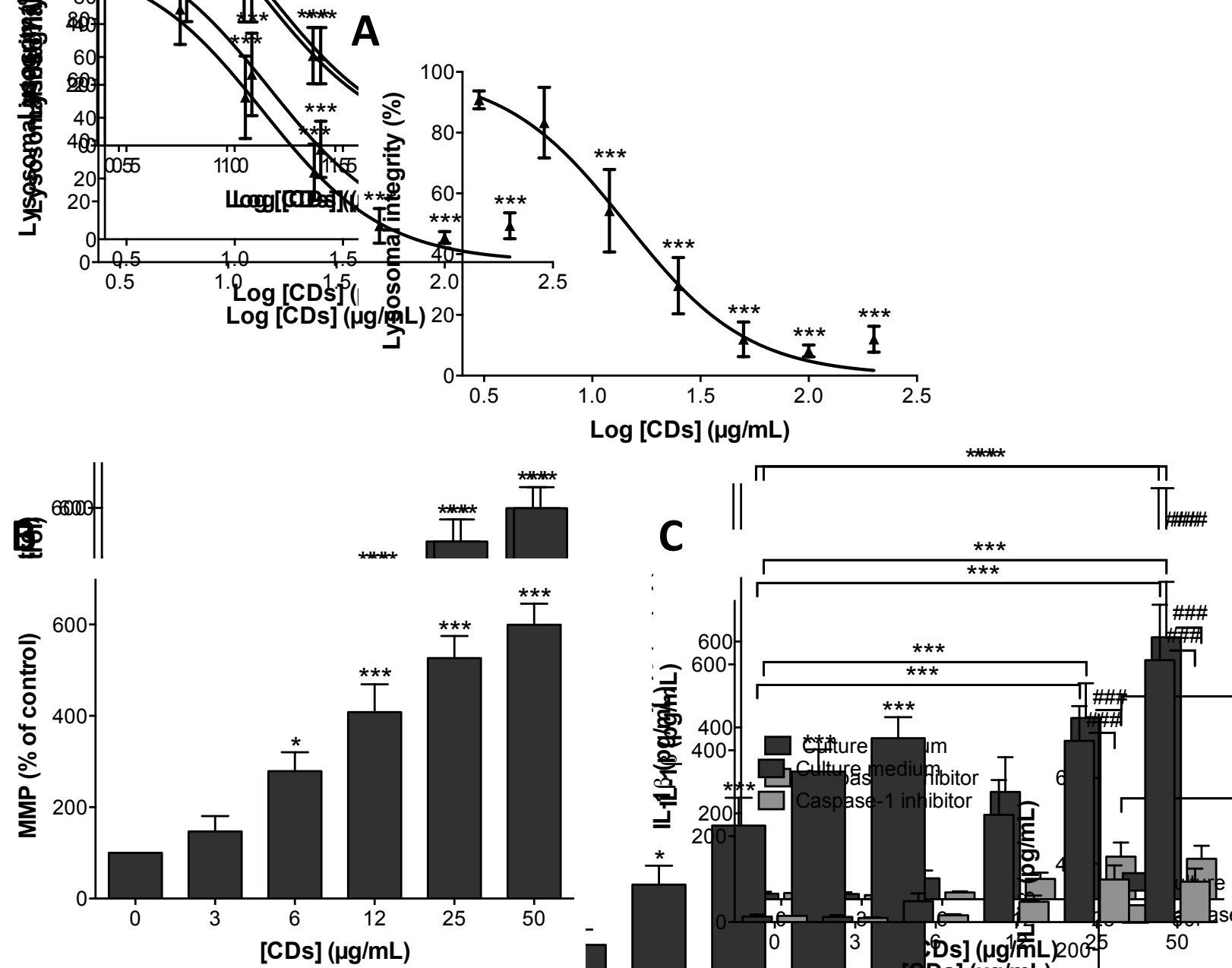

D
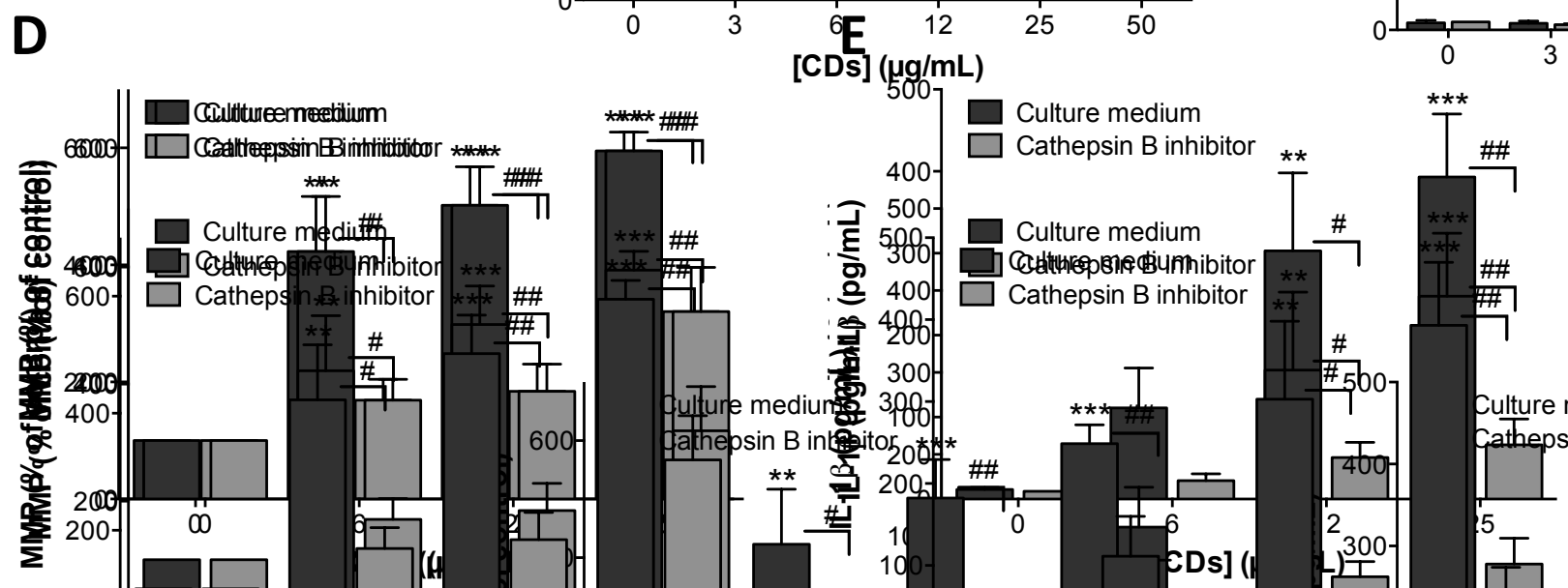